Special Issue of the 6th International Congress \& Exhibition (APMAS2016), Maslak, Istanbul, Turkey, June 1-3, 2016

\title{
Physical and Mechanical Properties of Silica Fume and Calcium Hydroxide Based Geopolymers
}

\author{
N.U. KockaL*, O. Beycan and N. Gulmez \\ Akdeniz University, Department of Civil Engineering, 07058, Antalya, Turkey
}

\begin{abstract}
Conventional portland cement has found worldwide usage in the production of cementitious materials in recent years. Nevertheless, environmental problems such as high demand of raw materials, energy consumption and high amount of carbon dioxide emission take place before and during manufacturing process. The attempts have been made to seek alternative binders and develop supplementary materials for construction sector. Therefore, this study reports the results of an experimental program on the comparison of geopolymers with different compositions in terms of evaluating their physical and mechanical behavior. For that purpose, the effect of binder types and amount of binders and alkali activator (sodium hydroxide) was investigated. In addition, acidic pumice and waste aluminium particles were also used as fine aggregate and air entraining agent, respectively, in geopolymer production. The test results revealed that as the content of alkali activator increased, compressive and flexural strength decreased. Addition of waste aluminium particles decreased bulk density and strength owing to the some extent of entrained air.
\end{abstract}

DOI: $10.12693 /$ APhysPolA.131.530

PACS/topics: 81.20.-n

\section{Introduction}

A large amount of $\mathrm{CO}_{2}$ is generated during the manufacturing process of cement, and this has significantly affected global warming and atmospheric pollution [1]. Alkali-activated binders generate $80 \%$ less carbon dioxide than portland cement [2]. "Alkali-activated binders" are also known as "geopolymers", as they were first named by Davidovits in the 1970s [3]. Geopolymers may be considered as environmentally friendly materials, since the production of geopolymer cement does not contribute to the appearance of greenhouse gases [4]. Geopolymers are considered to be a group of modern aluminosilicate materials of composition and properties allowing their application in numerous new technologies [5]. Geopolymers can be produced by a geopolymeric reaction of alkali activating solution (hydroxides, silicates, carbonates) with silica- and alumina-rich source materials of geological origin or pozzolanic materials [6], such as metakaolin [7], fly ash [8], rice husk ash [9], silica fume [10], slag [11], red mud [12], etc., which can react also with lime in the presence of moist, when they are finely milled (particle fractions under $0.075 \mathrm{~mm}$ ) [13].

Geopolymerisation involves a chemical reaction between various alumino-silicate oxides with silicates under highly alkaline conditions, yielding polymeric $\mathrm{Si}-\mathrm{O}-\mathrm{Al}-\mathrm{O}$ bonds, indicating that any $\mathrm{Si}-\mathrm{Al}$ materials could become sources of geopolymerisation [2]. Geopolymerisation is based on alumino-silica chain. It is a polymeric reaction that takes place between certain amount of alumina and silica in the presence of a strong alkaline solution $(\mathrm{NaOH}$, $\mathrm{KOH}$, water glass or their combination, etc.). Geopoly-

*corresponding author; e-mail: ukockal@yahoo.com merisation is often referred as alkali activation. It transforms the amorphous ingredients of materials into a composite that has strong binding property [14].

The main objective of this research was to investigate the physical and mechanical behavior of geopolymer mortar using silica fume and calcium hydroxide binders, acidic pumice as fine aggregate and waste aluminium particles as air entraining agent. For that purpose, the effects of binder types, amount of binders and alkali activator/solid ratio on air-entrained and non-entrained geopolymers were also examined.

\section{Experimental procedure}

Silica fume was supplied from Antalya Etibank Ferrochrome Factory located in west-southern Turkey. The specific gravity of silica fume was 2.25. Calcium hydroxide $\left(\mathrm{Ca}(\mathrm{OH})_{2}\right)$ produced by Dirmil Company was used in the preparation of the mixtures. The specific gravity of the calcium hydroxide was 2.35 . In the laboratory experiment, sodium hydroxide $(\mathrm{NaOH})$ with more than $99 \%$ purity was used as an alkali activator. Molecular weight of activator is $40 \mathrm{~g} / \mathrm{mol}$.

Acidic pumice aggregate was obtained from Burdur, Turkey and was used as fine aggregate. The specific gravity of the acidic pumice aggregate was 2.13. Fine aggregates were tested in oven-dry condition, utilizing the shoveling and rodding procedure, to determine the unit weight (loose and rodded) and void content, according to ASTM C 29-97. Loose and rodded unit weight of fine aggregates was $1.26 \mathrm{~g} / \mathrm{cm}^{3}$, and $1.38 \mathrm{~g} / \mathrm{cm}^{3}$, respectively.

Al-particles were provided as waste from metal processing and forming industry. Al-particles were used as $0.01 \%$ by weight of total mixture, to create air entraining in geopolymer. The specific gravity of Al-particles was 2.71 .

Mixing procedure was as follows. The sodium hydroxide $(\mathrm{NaOH})$ solution with concentration of $6 \mathrm{M}$ was 
prepared by dissolving $\mathrm{NaOH}$ pellets in distilled water in a volumetric flask. Next, the acidic pumice and $\mathrm{NaOH}$ solution were mixed for $30 \mathrm{~s}$. Calcium hydroxide was added into the mixture and mixed for another $30 \mathrm{~s}$. The mixture was stirred for a further 3 minutes with the addition of silica fume. Aluminium particles were then introduced into the mixtures and mixed for another $1 \mathrm{~min}$.

Mix proportions and notations are shown in Table I. The specimens were cast in $40 \times 40 \times 160 \mathrm{~mm}^{3}$ metal molds using a vibration method to eliminate entrapped air and were kept in these molds until they reached to sufficient hardness to be handled. The top of the molds was sealed with a plastic sheet to prevent evaporation of water during storage. Afterwards, demoulded specimens were immersed in a laboratory-type hot water tank to be cured.

TABLE I

Mix design of silica fume and calcium hydroxide based geopolymer (SCBG) specimens (by volume).

\begin{tabular}{c|c|c|c|c}
\hline \hline Mix & $\begin{array}{c}\text { Alkali } \\
\text { activator } \\
{\left[\mathrm{dm}^{3}\right]}\end{array}$ & $\begin{array}{c}\text { Silica fume } \\
{\left[\mathrm{dm}^{3}\right]}\end{array}$ & $\begin{array}{c}\text { Acidic pumice } \\
{\left[\mathrm{dm}^{3}\right]}\end{array}$ & $\begin{array}{c}\text { Calcium } \\
\text { hydroxide } \\
{\left[\mathrm{dm}^{3}\right]}\end{array}$ \\
\hline M1 & 400 & 50 & 350 & 200 \\
M2 & 450 & 50 & 300 & 200 \\
M3 & 450 & 50 & 200 & 300 \\
M4 & 450 & 100 & 200 & 250 \\
M5 & 500 & 50 & 300 & 150
\end{tabular}

Oven-dry (OD) bulk density and the saturated surface dry (SSD) bulk density values were obtained by testing $40 \times 40 \times 160 \mathrm{~mm}^{3}$ prism specimens according to ASTM C 642 .

The flexural and compressive strength of hardened specimens were determined in accordance with TS EN 101511. The flexural strength of a hardened specimen was evaluated by three point loading of a $40 \times 40 \times 160 \mathrm{~mm}^{3}$ prism specimen. Subsequent to the failure and breakage of this specimen, the compressive strength was determined on each half of the prisms.

\section{Results and discussions}

OD bulk density and the SSD bulk density test results of specimens are shown in Figs. 1 and 2. M5A specimens had the highest water absorption and porosity. However, the lowest OD bulk density was obtained in the same specimens. In contrast, M4 specimens had the lowest porosity and the highest OD bulk density. In fact, higher bulk density values were expected for M1 specimens, having the lowest alkali activator content. However, this could be attributed to the stiff consistency resulting in inappropriate compactibility and moulding. This led to increase in volume of entrapped air.

The bulk density values decreased while water absorption and porosity enhanced. Ghosh and Ghosh [15] sta-

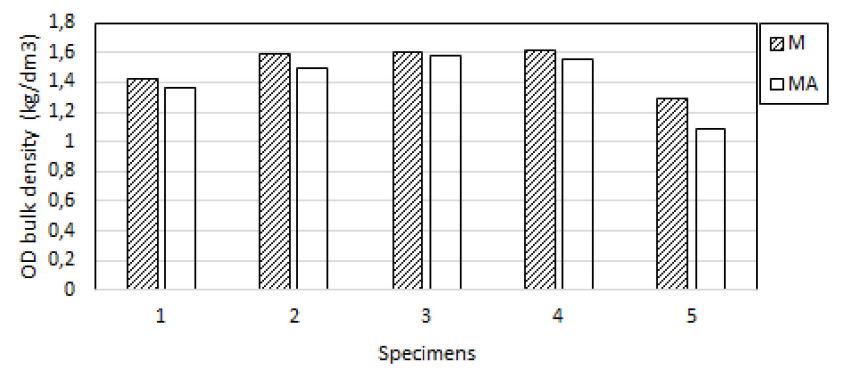

Fig. 1. OD bulk density values of SCBG specimens.

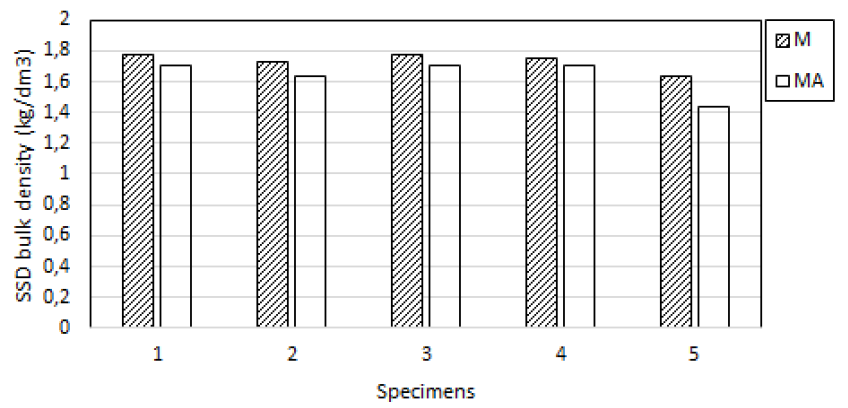

Fig. 2. SSD bulk density values of SCBG specimens.

ted that the apparent porosity and sorptivity as well as microstructure depended basically on alkali content and silica content. They also found that generally there was decrease in water absorption with increase in compressive strength and bulk density. However, specimens containing aluminium particles, because of slightly larger air voids, were lighter than non-air-entrained specimens and disregarding air entrainment, specimens having same composition with and without Al-particles had almost same water absorption ratio. In particular, the mixtures having the ratio of $450 \mathrm{dm}^{3}$ of alkali activator, specimens containing small amounts of calcium hydroxide and large amounts of silica fume and acidic pumice were determined to have low bulk density and high porosity. This is because, it is possible to connect the extra gel formation along with the specific weight of the components used.

Figures 3 and 4 give the mechanical properties of specimens. Specimens have shown flexural strength varying from 0.43 to $1.24 \mathrm{MPa}$, whereas the differences in compressive strength results were in a wide range, varying from 4.49 to $22.8 \mathrm{MPa}$. However, strength gain in molds for specimens having high alkali activator and pumice contents and low silica fume and calcium hydroxide amounts was very slow, causing prolonged demoulding time.

A decrease in flexural strength of $9.17 \%, 5.74 \%, 23.3 \%$, $25 \%, 37.7 \%$ for M1A, M2A, M3A, M4A, M5A mixes, respectively were observed according to their non-entrained counterparts. A decrease in compressive strength of $27.3 \%, 20.7 \%, 25.8 \%, 30.1 \%, 21.5 \%$ for M1A, M2A, M3A, M4A, M5A mixes, respectively were observed according to their non-entrained counterparts.

Compressive strength was reduced, as alkali activator/solid ratio increased. There are some controversial 


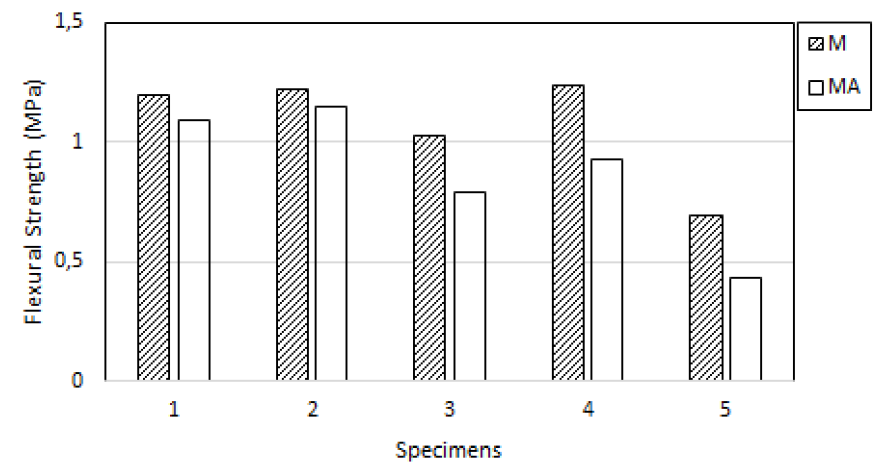

Fig. 3. Flexural strength of SCBG specimens.

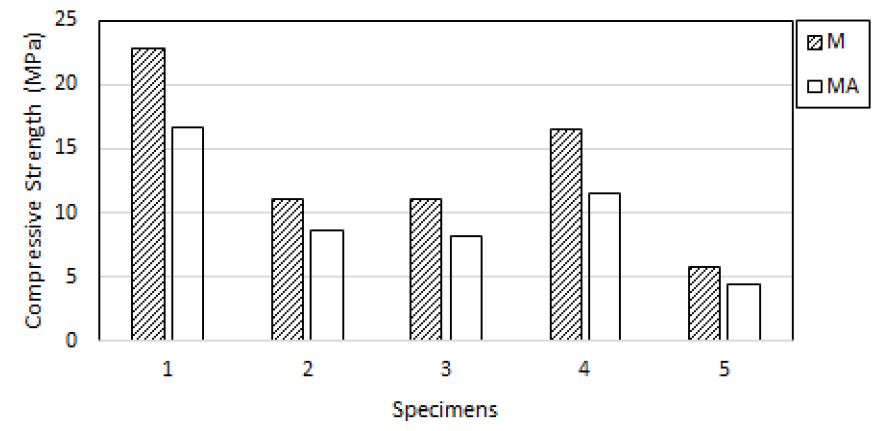

Fig. 4. Compressive strength of SCBG specimens.

statement for effect of activator-solid ratio on strength. Shekhovtsova et al. [16] indicated that the compressive strength of alkali-activated cement pastes was significantly affected by the activator-to-binder-solids ratio and the compressive strength decreased with an increase in activator-to-binder-solids ratio. In contrast, Jansen and Christiansen [17] found that the activator-solids ratios did not have a significant impact on the compressive strength or microstructure of the mortars. When dosage of alkali activator was kept constant, compressive strength did not change with the increase of lime, whereas strength decreased with the decrease of silica fume. Despite acidic pumice had fine grain size and a certain amorphous structure, contributing to reactivity, the results were not in support of this case. In other words, acidic pumice behaved as a non-reactive inert material. Silica from acidic pumice and silica fume and calcium from lime led to different types of gel occurrence. In a previous investigation proving this finding, it was stated that $\mathrm{C}-\mathrm{N}-\mathrm{A}-\mathrm{S}-\mathrm{H}$ type gel was found to be the main reaction product, possibly along with C-A-S-H type gel [18]. NA-S-H type gel was not distinguished at early age. Khater [19] found that the strength increase with silica fume up to $7 \%$ was due to highly effective pozzolanic activity of silica fume [20, 21] which improves such properties, like compressive strength, bond strength, and abrasion resistance, assuming silica fume to be as the reactant to produce secondary C-S-H, by consuming calcium hydroxide.

\section{Conclusions}

Following conclusions can be drawn from the experimental study:

- Setting time of specimens having higher amount of sodium hydroxide was prolonged. In addition, workability had increased with the increase of the sodium hydroxide content.

- Continuous large channels (open porosity) were formed through the outer part of the specimens, due to the coarse size of Al-particles. Although the reduction of bulk density was expected with inclusion of aluminium particles, a remarkable difference was not observed due to the pore structure formed. The maximum change in the value of OD bulk density and SSD bulk density of air-entrained specimens was found to be $15.5 \%$ and $12.2 \%$, respectively, according to their non-entrained counterparts.

- Strength had increased with addition of silica fume and with increase in activator amount. While the alkali activator content was kept constant, strength increase was entirely due to the enhanced content of silica fume.

- Shrinkage is also a key factor for geopolymers. Thus, investigations about the reducing of the shrinkage should be conducted on the same constituents by taking physical and mechanical properties into consideration.

\section{References}

[1] N.K. Lee, J.G. Jang, H.K. Lee, Cement Conrete Comp. 53, 239 (2014).

[2] F.P. Torgal, D. Moura, Y. Ding, S. Jalali, Constr. Build. Mater. 25, 3732 (2011).

[3] H. Yan, C. Xue-Min, M. Jin, L. Le-Ping, L. XingDong, C. Jin-Yu, Micropor. Mesopor. Mat. 161, 187 (2012).

[4] A.I.I. Helmy, Constr. Build. Mater. 110, 54 (2016).

[5] W. Mozgowa, J. Deja, J. Mol. Struct. 924-926, 434 (2009).

[6] V. Sata, A. Sathonsaowaphak, P. Chindaprasirt, Cement Concrete Comp. 34, 700 (2012).

[7] M.L. Kumar, V. Revathi, Constr. Build. Mater. 114, 1 (2016).

[8] D. Adak, M. Sarkar, S. Mandal, Constr. Build. Mater. 70, 453 (2014).

[9] Y.Y. Kim, B.J. Lee, V. Saraswathy, S.J. Kwon, Scientific World J. 2014, 209584 (2014).

[10] N.U. Kockal, C. Oguz, 9. Ulusal Beton Kongresi, Antalya, Türkiye 2015, p. 303.

[11] M.J. Nadoushan, A.A. Ramezanianpour, Constr. Build. Mater. 111, 337 (2016).

[12] M. Vukcevic, D. Turovic, M. Krgovic, I. Boskovic, M. Ivanovic, R. Zejak, Mater. Technol. 47, 99 (2013). 
[13] N.U. Kockal, Indian J. Eng. Mater. S 22, 203 (2015).

[14] C.D. Atis, E.B. Gorur, O. Karahan, C. Bilim, S. Ilkentapar, E. Luga, Constr. Build. Mater. 96, 673 (2015).

[15] K. Ghosh, P. Ghosh, IOSR Journal of Engineering (IOSRJEN) 2, 96 (2012).

[16] J. Shekhovtsova, E.P. Kearsley, M. Kovtun, J. S. Afr. Inst. Civ. Eng. 56, 44 (2014).

[17] M.S. Jansen, M.U. Christiansen, World of Coal Ash (WOCA) Conference in Nasvhille, 2015.
[18] S. Zhang, A. Keulen, K. Arbi, G. Ye, An ECI Conference, 2015, p. 48.

[19] H.M. Khater, The 2014 World Congress on Advances in Civil, Environmental, and Materials Research (ACEM 14), Busan, Korea (2014).

[20] N.U. Kockal, F. Turker, Constr. Build. Mater. 21, 634 (2007).

[21] N.U. Kockal, IJST, Transactions of Civil Engineering 37(C1), 67 (2013). 